\title{
Determinants of Breastfeeding Patterns among Women in South West Nigeria.
}

\author{
Olurotimi Joseph Ogunlade, Phd \\ Dept. of Educational Psychology Islamic University In Uganda Mbale Uganda.
}

\begin{abstract}
The study investigated the determining factors that account for different types of breastfeeding methods among Women in South West Nigeria. The research design used was the descriptive research design of the survey type. The population for the study was made up of women with breastfeeding experience. The sample consisted of 1,385 women selected from three states in South West Nigeria. Multistage random sampling technique was used. The research instrument used was titled Determinants of Breastfeeding Pattern among Women (DBPW). The instrument was valid and reliable; it was construct validated and a split half reliability coefficient of 0.87 was obtained. The study was carried out to exposed mothers to the realistic expectation of their infant's breastfeeding behavior to support the decision to breastfeed and avoid unnecessary supplementation. Specifically, the study examined the different breastfeeding methods adopted with respect to mothers' education and employment status. From literature it was observed that despite exclusive breastfeeding being the optimal way of feeding an infant, the percentage of mothers who exclusively breastfed drop from over $75 \%$ who initiate to less than $11 \%$ at six months, well short of the Healthy People 2010 initiative goal of 50\% of infants being exclusively breastfed for six months. The result of the findings revealed that women with high level of education were not well disposed to exclusive breastfeeding; so also, women that are government and private company employees found it very difficult to engage in full breastfeeding. It was concluded that unfriendly working environment can make it difficult to breastfeed on demand. Hence it was recommended among others that the present level of public campaign is stepped up.
\end{abstract}

Key words: Breastfeeding Patterns, Determinants, South West Nigeria.

\section{Introduction}

There is no doubt: Breast milk is the best. Breast milk is the ideal nutrition for the babies because it contains all nutrients the baby needs for the first six months of life and helps them to grow up healthy. No other milk, food, drink or even water is required. Besides, breastfeeding according to WHO (2010) confers a substantial health benefits on both mother and child. Breast milk reduces infant mortality by the fact that it provides immunological protection against childhood diseases. For the mother, breastfeeding encourages the involution of the uterus tube and thus the rapid return of the uterine tomb which helps the mother to regain her natural shape after birth. It promotes an affectionate bond between mother and child. It also delays the return of normal ovarian function and thereby lengthens the intervals between births.

In spite of the aforementioned benefits of breastfeeding, women in the south west were observed to be deeply involved in all acts or behavior that negates breastfeeding. Such as psychological and cultural changes, some women abandon breastfeeding in other to maintain their youthful outlook in a bid not to develop a flabby breast, more so that it is perceived as an erotic zone. Even nursing mothers find it difficult to expose their breast in the public, some mothers complain of insufficient breast milk. Some literate women were observed to have seen breastfeeding as an archaic process most especially while in transit or in a public social functions. This phenomenon seems to be social activities which are under the control of norms and standards of social practices and expectations. This may constitute activities which provide support for mother's choice to breastfeed based on the behavior that is healthiest for her and her new born baby. Thus women have adopted varied patterns of breastfeeding commonly referred to as exclusive breastfeeding and supplementary (bottled, scheduled or clustered) breastfeeding.

It is expedient to let mothers understand that they need to have realistic expectation of their infant breastfeeding behavior to support the decision to breastfeed and avoid unnecessary supplementation. Kent (2013), in his study about infant breastfeeding pattern, opined that there is a wide variation in normal breastfeeding behavior and mother should be able to demonstrate the changes they can expect during exclusive breastfeeding period. For instance, mothers' perception of milk supply may be based on infant behavior and whether that matches the expectation of the mothers. If these expectations are based on the behavior of formulafed infants then the expectation are likely to be unrealistic for a breastfed infant. If these expectations are not met the mother may lose confidence in her breastfeeding. A loss of confidence is a major factor in the decision to cease breastfeeding or introduce supplementary feeds.(Flores-Quijano,2008). In short, the longitudinal and cross sectional studies of Hauk (2011) and Kent (2013) dispel any belief that breastfeed infants follows the same 
patterns of breastfeeding behavior as formula -fed infants and they went further to reassure mothers that changes in their infant's breastfeeding behavior are normal and not an indication of insufficient milk.

In view of this, several authorities and experts have adduced a lot of reasons for this unhealthy behavior. For example, Nag (2003) associate the decline in breastfeeding to changes in socio-economic conditions especially women's education and the new roles been occupied by women in our contemporary societies. Odu (2012) identified urbanization, industrialization, infant food industry marketing pressures biases toward bottle feeding and confusing instruction from the medical professional. It was equally observed that eradication of traditional values and modes of living such as decline in extended family system and the employment of women in far away places of abode and pressure to return to work shortly after delivery were seen as factors that made breastfeeding on demand difficult for women.

Meanwhile, WHO (2010), UNICEF (2008) and Bellagio Consensus (1988) have all agreed that nursing mothers should breastfeed exclusively for the first 6 months of life of the baby in an attempt to guarantee good and sound health for the child and mother. It is against this background the researcher attempted to examine the type of feeding method engaged in by mothers and the possible reasons behind their informed decisions with the sole aim of preventing the side effects on the sustainable growth and development of the baby alongside the health of the mother.

\section{Statement of the Problem.}

From literature the researcher observed that the incidence and duration of breast feeding is declining among women. Thulier and Mercer (2009) opined that the percentage of mothers who exclusively breastfeed drops from $75 \%$ who initiate to less than $11 \%$ at six months which was well short of the Healthy People 2010 Initiative goals of 50\% of infants being exclusively breastfeed for six months. The researcher also observed that women in South West Nigeria seems breastfeeding far below the submission of Bellagio Consensus (1995), WHO (2001) that women must breastfeed their babies exclusively for the first six month of life. Although Hawk (2011) asserted that the frequent reason given by mothers for ceasing breastfeeding is a perception of insufficient milk supply. Meanwhile the researcher felt that a reduction in the incidence and duration of breastfeeding may be dangerous to the health of the mother and the child .Hence this research work specifically examined the different patterns of breastfeeding with respect to mother's level of education and employment status.

\section{Hypotheses.}

The courses of this study was guided by the following hypotheses and were tested at 0.05 level of significance.

HO1 There is no significant difference in the breastfeeding duration of South West Nigeria women based on their level of education.

HO2 Occupation of women in South West Nigeria will not significantly influence the length of her breastfeeding duration.

\section{Purpose of the Study}

The reason behind this study is to expose mothers to the realistic expectations of their infant's breastfeeding behavior to support the decision to breastfeed and avoid unnecessary supplementation. Specifically the objective was to determine the breastfeeding pattern adopted by South West Nigeria women with recourse to their level of education and type of employment.

\section{Methodology}

The research design used was the descriptive research design of the survey type. The population for the study was made up of women with breastfeeding experience. The sample consisted of 1,385 women selected from three states in South West Nigeria. Multistage random sampling technique was used. The research instrument used was titled Determinants of Breastfeeding Pattern among Women (DBPW). The research instrument consisted of two sections A and B. Section A consist of social characteristic of the respondent such as religion, sex of their children, age, location of residence, educational qualifications and some background information such as birth interval, method of feeding. Section B consists of 25 items on pattern of feeding and determining factors. The instrument was construct validated and a split half reliability coefficient of 0.87 was obtained. Research assistants and the researcher administered the questionnaire. The Data was analyzed using inferential statistic such as ANOVA to test the hypotheses at 0.05 level of significance.

\section{Results and Discussion.}

Hypothesis 1.There will not be a significant difference in the breastfeeding pattern of women based on their level of education. 
In order to test this hypothesis, the mean scores on breastfeeding pattern among women with different education background were compared and subjected to one way Analysis (ANOVA) 0.05 level of significance. The result is presented below;

Table 1: One way ANOVA summary of educational background and breastfeeding pattern among South West Nigeria Women

\begin{tabular}{|c|c|c|c|c|c|}
\hline Source & Ss & Df & Ms & F-cal & F- table \\
\hline Below groups & 1756.651 & 3 & 585.55 & \multirow[t]{3}{*}{57.55} & \multirow[t]{3}{*}{2.60} \\
\hline Within groups & 101839.45 & 1246 & 33946.483 & & \\
\hline Total & 103596.100 & 1249 & & & \\
\hline
\end{tabular}

$\mathrm{p}>0.05$

Table 1 shows that F-cal 57.55 was greater than F-2.60 the null hypothesis is rejected. $(\mathrm{F}=57.55$,

$\mathrm{P}<0.05)$ Therefore, education of women did significantly influence their breastfeeding pattern.

In order to determine the pair of groups that are significantly different at 0.05 level of significance, Scheffe Post-Hoc test was applied. The result is presented in Table 2.

Table 2 Scheffe Post-Hoc analysis of education and breastfeeding pattern among women in South West Nigeria

\begin{tabular}{|c|c|c|c|c|c|c|}
\hline & $\mathrm{N}$ & Mean & None & Primary & Secondary & $\begin{array}{l}\text { Higher } \\
\text { Education }\end{array}$ \\
\hline None & 519 & 16.22 & & $*$ & & $*$ \\
\hline Primary & 331 & 14.94 & & & & \\
\hline Secondary & 192 & 14.15 & & & & \\
\hline Higher education & 208 & 14.116 & & & & \\
\hline
\end{tabular}
p> 0.05

The mean difference is significant at 0.05 . Table 2 indicated that the mean difference in breastfeeding pattern and level of education between none educated and holders of primary school certificate was significant. Similarly, there was a significant difference in level of none educated and possessor of higher education at 0.05 level of significance.

Hypothesis 2, Occupation of women will not significantly influence there breastfeeding pattern.

To test the hypothesis mean scores on breastfeeding pattern were compared with their diverse occupation using one way Analysis of Variance (ANOVA) at 0.05 level of significance. The result is presented in table 3.

Table 3 One way ANOVA Summary of Occupation of Women and Breastfeeding Pattern.

\begin{tabular}{|l|l|l|l|l|l|}
\hline Source & Ss & Df & Ms & F-cal & F-table \\
\hline Between groups & 3113.218 & 3 & 1037.739 & \multirow{2}{*}{2.68} & \multirow{2}{*}{2.60} \\
\hline Within groups & 100482.900 & 1246 & 80.644 & & \\
\hline Total & 103596.100 & 1249 & & & \\
\hline
\end{tabular}

$\mathrm{P}<0.05$

Table 3 reveals that f-cal of 12.68 was greater than f-tab of 2.60 , the null hypothesis was rejected $(\mathrm{F}=12.68, \mathrm{P}<0.05)$ therefore, occupation of women will significantly influence their breastfeeding pattern. This means that occupation of the mother has significant influence on her breastfeeding pattern.

Table 4 Scheffe Post-Hoc Analysis of Women Occupation and Breastfeeding Pattern in South West Nigeria.

\begin{tabular}{|l|l|l|l|l|l|l|}
\hline Occupation & N & Mean & Government work & Private company & Self Employed & Unemployed \\
\hline Government work & 519 & 59.22 & & & & $*$ \\
\hline Private company & 331 & 60.46 & & & & $*$ \\
\hline Self Employed & 192 & 60.76 & & & & $*$ \\
\hline Unemployed & 208 & 63.79 & & & & $*$ \\
\hline
\end{tabular}
p> 0.05

*The mean difference is significant at 0.05 level.

Table 4 shows that there is a significant difference in the breastfeeding pattern of government workers and unemployed. Similarly, unemployed women are significantly different from those working with private company and self employed each at 0.05 level of significant.

\section{Discussion}

This study attempted picking a position in the New World Order by establishing a relationship between mothers' behavior toward their health and their baby with regards to breastfeeding. Responses of their 
breastfeeding pattern revealed that the attitude of the majority of women toward breastfeeding was positive. In order words this result suggests that most of the women have desirable behavior, all other hindrances notwithstanding. This finding is consistent with the existing literature that breast milk is an excellent source of nutrition for the baby and promotes an affectionate bond between mother and child.( Odu and Ogunlade, 2011; WHO, 2008; UNICEF,2010; WABA, 2010,).

Specifically, the finding of this study made it clear that level of education is a very important determining factor of breastfeeding pattern among women. Supporting this finding is the explanation of Ogunmodimu (2010) that the better educated a woman is, the higher her socio economic status and the less likely she is to start breastfeeding and if she starts, on average, she breastfeed for a shorter period. The effect of this on women breastfeeding pattern according to this result is curvilinear. The result shows that relative to those mothers who have no education, have shorter breastfeeding duration. The mean distribution indicated that both the secondary and higher education categories do influence the breastfeeding pattern.

The report of Oni (1998) negates this result as he submitted that women with no formal education breastfeed for over twenty months while women with post secondary education stopped breastfeeding at about seven months. To conclude this section is the analysis of Duncan (2004), he explain that the association between education and socio economic status on one hand and breastfeeding pattern on the other hand cannot be proved to have causal effect in his study, nonetheless the association suggest that as urbanization, education and standard of living increase, the overall practice of breastfeeding will decrease unless other changes counteract them.

The analysis of hypothesis two reveals that there is a significant relationship between the job the mother does and her breastfeeding pattern. There are lots of literatures supporting this finding, e.g Huffman (2009) asserted that the type of work a woman engage in can influence breastfeeding by affecting both her access to the baby and the time available with the baby. The decision to breastfeed is affected by the compatibility of the mother's job with child care and breastfeeding.

If women have their children within their work setting, for example, through nearby day care centers, or crèches in their work place, and if her work is flexible and allows nursing breaks, women are more likely to have access to their children they would have been able to breastfeed better and longer. Oluwadare (1999) concludes this part by arguing that women's work status may also affect the duration of breastfeeding by reducing the length of full breastfeeding. When women's work is incompatible with child bearing, they may reduce the duration of breastfeeding, which may lead to different types of feeding infants.

\section{Conclusion.}

In conclusion, to comply with the New World Order on global health issue with reference to breastfeeding, education which is synonymous to the social class that one belongs to in the society and the type of employment one does and the level of environment one operates the need therefore be that educated mothers should be encouraged to utilized their education to appreciate the importance of breastfeeding to the extent that the illiterate mothers will even use them as a reference point to breastfeed for a longer period. Finally, credence must be given to breastfeeding -friendly policies, moreover that the finding reveals that an unfavorable working environment can make it difficult to implement breastfeeding measure. It is therefore very important that woman work "productive role" and family "productive role" be respected and accommodated by the society.

\section{Recommendation.}

Consequent upon the findings of this research work it is hereby recommended that to enhance the practice of longer breastfeeding duration, massive promotion of breastfeeding through the mass media, support groups for breastfeeding women, better life program, village groups and education in schools should be embarked upon. Health practitioners should also give appropriate information during antenatal care stressing the importance of longer period of lactation especially for the health of the baby. It is equally recommended that government and private employers of labour should also create a friendly working environment such as establishing a cretche and possibly increase the maternity leave period from 3 to 6 months.

\section{References}

[1]. Bellagio Consensus (1995) Breastfeeding as a Family Planning Method, The Lancet; 205(52 42): 1221-1231

[2]. Duncan J F (2004) Women's Decision About Breastfeeding and Maternal Employment. Journal of Marriage and the Family, 58: 239-251

[3]. Flores-Quijano ME, Cordova A, Contreras-Ramirez V, Farias-Hernandez L, Cruz TM, Casanueva E. (2008) Risk for postpartum depression, breastfeeding practices, and mammary gland permeability. J Hum Lact, 24:50-57.

[4]. Hauck YL, Fenwick F, Dhaliwal SS, Butt J. (2011) A western Australian survey of breastfeeding initiation, prevalence and early cessation patterns. Matern Child Health J 15:260-268.

[5]. Hoffman E F (2009) Peer Counsellor Program increasing breastfeeding rates in Utah Native American WIC Population. Journal of Human Lactation, 11(4): 279-284 
[6]. Kent JC, Hepworth AR, Sherriff JL, Cox DB, Mitoulas LR, Hartmann PE. (2013) Longitudinal changes in breastfeeding patterns from 1 to 6 months of lactation. Breastfeed Med 8:401-

[7]. 407

[8]. Kent JC, Mitoulas LR, Cregan MD, Ramsay DT, Doherty DA, Hartmann PE. (2006) Volume and frequency of breastfeedings and fat content of breast milk throughout the day.

[9]. Pediatrics 117:387-395.

[10]. Odu B K, Ogunlade J O. (2011) Breastfeeding and Child Spacing Among Women in South West Nigeria. Journal of CrossDisciplinary Subjects in Education (IJDSE) volume 2, 414-420

[11]. Odu B K, (2012) Atittude and Practice of Breastfeeding among Women South West Nigeria.London International Conference in Education, Proceedings. 228-235.

[12]. Ogunmodimu (2010) Maternal Infant St. Louis, M O. Mosby Oluwadare, C. T. (1999) Maternal; and Child Health Care: A study of Morbidity and mortality pattern in Ido-Osi LGA of Ekiti State Nigeria. M. Sc. Thesis Department of Sociology, University of Ibadan, Ibadan.

[13]. Oni, G. A (1998) Use of contraceptives for birth spacing in a Nigerian city studies in family planning 17, No. 4 (July/August): 165171

[14]. Thulier D \& Mercer J (2009) Variables associated with breastfeeding duration. J Obstet Gynecol Neonatal Nursing, 38:259-268.

[15]. UNICEF (2008) Lactational Amehnorrhea Method (LAM) Publication of Georgia University, Institute of Reproductive Health.

[16]. WABA (2010) Consensus Statement on the use of Breastfeeding as Family Planning Method. Contraception, 39: 477-496

[17]. World Health Organization (1992) Factors influencing decision to breastfeeding. Journal of Advance Nursing, 468369-79 